\section{What really matters is the menopausal woman!}

Yet again scientists and epidemiologists are publicly debating the controversies around the previously reported risks of HRT (hormone replacement therapy). Is this further publicity deserved? The impact of studies such as the Million Women Study (MWS) $)^{1}$ and Women's Health Initiative (WHI) ${ }^{2}$ has been profound, leading to significant reductions in the use of HRT. This has understandably affected millions of menopausal women globally who deserve to be fully informed of any doubts that may exist concerning the studies and should be aware of the debate. ${ }^{34}$

Ever since these papers were published the headlines in the popular press have been biased towards the 'bad news' messages, resulting in our patients feeling confused and under pressure to stop HRT. Following a recent web-based survey $70 \%$ of women who came off their HRT were below the age of 50 years. More importantly, had these women known what we know today, $45 \%$ would have stayed on treatment. ${ }^{5}$

Many patients have been advised by their doctors to stop HRT and in some cases have had their prescriptions unilaterally withdrawn. These women have sought additional, poorly researched products with unproven safety and efficacy - often sold as food supplements to circumvent regulatory authorities.

Which risk is greatest? Taking a treatment that has little evidence of effectiveness or safety, or taking a product with the enormous research base that applies to HRT? Do we really know the answer? Is there enough information to allow carers or patients to be fully informed? We believe that the risk, if any, is small and it is the view of the British Menopause
Society (BMS) that, when used appropriately, any risks are outweighed by the benefits for the majority of women.

We must not forget that at the centre of the current published arguments there are millions of women who want to be properly informed about whether they should be taking HRT. Further, there are likely to be thousands of doctors and nurses who want to be more knowledgeable and confident about prescribing HRT.

In recognition of the menopause having diverse consequences, and in an attempt to improve the provision of essential information for women, the BMS has recently submitted recommendations to the Department of Health. The key recommendation is that women should, around the time of the menopause transition, have a formal assessment of their needs, including advice concerning lifestyle, diet and individualised discussion of the risks and benefits of any suitable hormonal therapies. The BMS also suggested that while this would require additional resources, the potential long-term health gains would make this consultation highly cost effective in disease prevention terms. ${ }^{6}$

The two main areas that require addressing urgently are as follows:

\section{1) A robust understanding of the benefits and risks of HRT for patients and carers}

Most women who have been taking HRT since the publication of WHI and MWS will have been doing so having weighed up the pros and cons of treatment. Many women, even if there were genuinely a small increased risk of breast cancer, would accept this, if they could have a good quality of life through relief of the debilitating symptoms that invariably affect personal, social and wider quality of life.

The clear benefits in osteoporosis treatment and prevention have recently been included in a recommendation from the National Osteoporosis Society that recommends HRT for the treatment and prevention of osteoporosis in women under 60 years of age.

\section{2) HRT is not a single drug as the} press and our patients seem to have derived from the publicity

HRT is a comprehensive suite of preparations and delivery routes produced by the pharmaceutical industry in response to women's needs over more than 20 years of development, refinement and research. This research continues, even though research funding is a fraction of what it once was. ${ }^{8}$

Recently completed trials not only suggest that natural progesterone may not affect the risk of breast cancer and have a neutral effect, ${ }^{9}$ but also that soon to be released small studies of lower 
dose, endogenous-type hormone treatments given to recently menopausal women show great promise. ${ }^{10}$

The BMS feels that the research must continue. As the female population lives longer after the menopause we need to establish safe ways to prevent disease and maintain a high quality of life. This requires a trial to establish definitively the correct indications, patients and hormones for optimal postmenopausal health. ${ }^{11}$ We should harness the wealth of knowledge from the debates around WHI and MWS to design this study rather than watch the arguments from the sidelines.

The BMS is dedicated to advancing education in all matters relating to the menopause and to the primary prevention of the burden of preventable chronic disease.

Nick Panay, MRCOG, MFSRH

Chairman, British Menopause Society; Consultant Gynaecologist, Queen Charlotte's and Chelsea \& Westminster Hospitals, Honorary Lecturer, Imperial College London, London, UK: nickpanay@msn.com

Heather Currie, FRCOG, MRCGP

Medical Advisory Council Member, British Menopause Society; Associate Specialist Gynaecologist, Dumfries and Galloway Royal Infirmary, Dumfries, UK; Medical Director, 'Menopause Matters'; heather.currie@nhs.net

Edward Morris, MD, FRCOG

Medical Advisory Council Member, British

Menopause Society; Consultant in Obstetrics \& Gynaecology, Norfolk \& Norwich University Hospital, Norwich, UK; edward.morris@nnuh.nhs.uk

Competing interests Nick Panay (NP), Edward Morris (EM) and Heather Currie (HC) have received sponsorship for lectures and advisory work performed for pharmaceutical companies. NP and $\mathrm{HC}$ have received educational grants for meetings and NP has received funding for pharmaceutical trials. NP is Co-editor-in-Chief of Climacteric (International Menopause Society journal) and EM/HC are Co-editors-in-Chief of Menopause International (British Menopause Society journal).

J Fam Plann Reprod Health Care 2012;38:136-137. doi:10.1136/fprhc-2012-100329

\section{References}

1 Million Women Study Collaborators. Breast cancer and HRT in the Million Women Study. Lancet 2003;362:419-427.

2 Writing Group for the Women's Health Initiative Investigators. Risks and benefits of estrogen plus progestin in healthy postmenopausal women: principal results from the Women's Health Initiative randomised controlled trial. JAMA 2002;288:321-333.

3 Shapiro S, Farmer RD, Stevenson JC, et al. Does hormone replacement therapy cause breast cancer? An application of causal principles to three studies Part 4: The Million Women Study. J Fam Plann Reprod Health Care 2012; 38:102-109.

4 Shapiro S, Farmer RD, Mueck A0, et al. Does hormone replacement therapy cause breast cancer? An application of causal principles to three studies: part 2. The Women's Health Initiative: estrogen plus progestogen. $J$ Fam Plann Reprod Health Care 2011:37:165-172.
5 Cumming GP, Currie HD, Panay N, et al Stopping hormone replacement therapy: were women ill advised? Menopause Int 2011;17:82-87.

6 British Menopause Society Council. Modernizing the NHS: observations and recommendations from the British Menopause Society. Menopause Int 2011:17:41-43.

7 Bowring CE, Francis RM. National Osteoporosis Society's Position Statement on hormone replacement therapy in the prevention and treatment of osteoporosis. Menopause Int 2011;17:63-65.

8 Panay N, Ylikorkala 0, Archer DF, et al. Ultra-low-dose estradiol and norethisterone acetate: effective menopausal symptom relief. Climacteric 2007; 10:120-131.

9 Fournier A, Fabre A, Mesrine S, et al. Use of different postmenopausal hormone therapies and risk of histology- and hormone receptordefined invasive breast cancer. J Clin Oncol 2008;26:1260-1268.

10 Harman SM, Brinton EA, Cedars M, et al. KEEPS: The Kronos Early Estrogen Prevention Study. Climacteric 2005;8:3-12

11 Panay N, Fenton A. Has the time for the definitive, randomized, placebo-controlled HRT trial arrived? Climacteric 2011;14:195-196. 